\title{
DESENVOLVIMENTO E DIREITOS HUMANOS: UM BALANÇO DOS 10 ANOS DO PROGRAMA NACIONAL DE DIREITOS HUMANOS (PNDH-3)
}

\author{
DEVELOPMENT AND HUMAN RIGHTS: A 10-YEAR BALANCE \\ OF THE NATIONAL HUMAN RIGHTS PROGRAM (PNDH-3)
}

André Luiz Faisting ${ }^{1}$

http://lattes.cnpq.br/8904120838149160

Vitor Hugo Rinaldini Guidotti ${ }^{2}$

http://lattes.cnpq.br/3171646123025674

http://orcid.org/0000-0001-9588-8142

Recebido em 26 de Outubro de 2019

Aceito em 16 de Dezembro de 2019

RESUMO: A Constituição Brasileira de 1988 apresenta como uma de suas características marcantes a relação intrínseca com a Declaração Universal dos Direitos Humanos de 1948. Após sua promulgação, algumas tentativas de apresentar ações mais objetivas em prol dos direitos humanos são materializadas em três diferentes versões do Programa Nacional de Direitos Humanos. O terceiro e último PNDH, ainda em vigor, apresenta uma série de diretrizes, orientações e ações para que o Estado brasileiro se encarregue de propiciar políticas públicas concatenadas com a dignidade da pessoa humana. O objetivo deste artigo foi analisar um dos eixos do PNDH-3, que versa sobre Desenvolvimento e Direitos Humanos. Para isso, buscou-se produzir um balanço entre o que foi originalmente proposto, em especial sobre a perspectiva de desenvolvimento pretendida à época, e os caminhos adotados pelos governos dez anos após a promulgação do PNDH-3. Um dos resultados mais significativos é o evidente descompasso entre o que foi proposto e a orientação econômica adotada pelos últimos governos. Desta forma, concluiu-se que não apenas os objetivos do PNDH-3 estão comprometidos, como também a normalidade democrática e a violação da Carta Magna, que tem na dignidade da pessoa humana um de seus princípios fundamentais.

Palavras-chave: Desenvolvimento; Direitos Humanos; PNDH-3; Estado; Economia; Desigualdade.

\begin{abstract}
The 1988s Brazilian Constitution presents as one of its main characteristics the intrinsic relationship with the 1948s Universal Declaration of Human Rights. After its promulgation, some attempts to present more objective actions in favor of human rights are materialized in three different versions of the Human Rights National Program. The third and last Human Rights National Program, still in force, presents a series of guidelines and actions for the Brazilian State to take charge of providing public policies linked with the dignity of the buman person. The purpose of this article was to analyze one of the axes of the third Human Rights National Program (PNDH-3), which deals with Development and Human Rights. Therefore we sought to produce a balance between what was originally proposed, especially about the development perspective intended at the time, and the paths adopted by go-
\end{abstract}

\footnotetext{
${ }^{1}$ Doutor em Ciências Sociais pela UFSCar e Professor do Curso de Graduação em Ciências Sociais e do Mestrado em Sociologia da UFGD. Endereço eletrônico: andrefaisting@ufgd.edu.br

2 Mestre em Sociologia pela UFGD e doutorando em Sociologia pela UFSCar. E-mail: vitor_guidotti@live.com
} 
vernments ten years after the promulgation of the PNDH-3. One of the most significant results is the evident mismatch between what was proposed and the economic orientation adopted by the previous governments. Therefore it was concluded that not only the objectives of the PNDH-3 are compromised, but also the democratic normality and the violation of the Magna Carta, which has in human dignity one of its fundamental principles.

Key-Words: Desenvolvimento; Direitos Humanos; PNDH-3; Estado; Economia; Desigualdade.

\section{INTRODUÇÃO}

Num contexto marcado por intensa polarização entre ideologias progressistas e defensoras dos direitos humanos, por um lado, e conservadoras e fundamentalistas, por outro, refletir sobre o significado e o alcance dos direitos humanos vai além da reflexão acadêmica e invade o campo do compromisso ético e social, já que as concepções que se colocam contrárias aos direitos humanos sugerem, pelo menos, duas constatações: desconhecimento ou irresponsabilidade. Ou seja, tanto o desconhecimento da importância histórica dos direitos humanos, cujo paradigma contemporâneo está contido na Declaração Universal de 1948, como a irresponsabilidade do discurso que criminaliza esses direitos, favorece e fortalece novas e velhas intolerâncias, tensões e violências.

Nesse sentido, é importante registrar que em dezembro de 2019 completam-se 10 anos do lançamento da terceira e última versão do Programa Nacional de Direitos Humanos. ${ }^{3}$ Apresentado à sociedade brasileira durante o segundo mandato do Governo Lula, o PNDH-3 foi o mais amplo e o mais polêmico entre as três versões. ${ }^{4} \mathrm{Não}$ por acaso a reação a esse documento foi imediata, o que obrigou o governo a recuar em várias propostas originais apenas alguns meses após o lançamento. ${ }^{5}$

Passados 10 anos, portanto, constata-se que as resistências às propostas do PNDH-3 não diminuíram nem se resolveram com as alterações efetuadas nos primeiros meses após o seu lançamento, o que demonstra que para além de algumas temáticas pontuais do texto original, o documento como um todo vem sendo gradualmente desconstruído pelo discurso e pelas políticas contrárias aos direitos humanos.

Considerando o contexto atual no qual os direitos humanos se tornaram alvo preferencial de ataques, esse artigo pretende oferecer um balanço das políticas e das violações de direitos a partir de um dos eixos orientadores do PNDH-3, qual seja, Desenvolvimento e Direitos Humanos. Antes, porém, apresentaremos uma breve descrição da trajetória do Programa Nacional de Direitos Humanos no Brasil, bem como das primeiras resistências ao PNDH-3 que, conforme constataremos, se ampliaram de forma significativa até o presente, não apenas em termos das mentalidades, mas também por meio de políticas e de efetivas violações de direitos.

O método empregado nesta pesquisa é a análise documental. Entre as fontes consultadas encontram-se documentos oficiais como decretos, leis constitucionais e infraconstitucionais, medidas provisórias, conteúdo de Ações Diretas de Inconstitucionalidade (ADI), decisões e discursos proferidos pelo Supremo Tribunal Federal (STF) e seus ministros, entre outros. Também foram contempladas na pesquisa matérias, notícias, entrevistas e artigos de opinião de relevantes fontes jornalísticas. A partir da fundamentação teórica e analítica, e com base

\footnotetext{
3 A terceira versão do PNDH foi lançada em 21 de dezembro de 2009 por meio do Decreto 7.037.

${ }^{4}$ As versões anteriores foram lançadas em 1996 e 2002, ambas durante o Governo FHC.

5 Por meio do Decreto 7.177, de 12 de maio de 2010, várias propostas do PNDH-3 foram revogadas e/ou alteradas.
} 
nos dados oriundos das fontes documentais, foi possível produzir um balanço entre o que estava previsto no terceiro Programa Nacional de Direitos Humanos (PNDH-3) (BRASIL, 2009) e suas alterações (BRASIL, 2010), em contraste com as decisões dos governos nos últimos 10 anos (2009-2019).

\section{O PROGRAMA NACIONAL DE DIREITOS HUMANOS NO BRASIL: ENTRE AVANÇOS E RETROCESSOS}

O reconhecimento e a incorporação dos direitos humanos no ordenamento social, político e jurídico brasileiro resultam de um processo de conquistas históricas que se materializaram na Constituição de 1988, um processo que revela um "longo caminho" marcado por avanços e retrocessos (CARVALHO, 2001). Dado o contexto mais recente de violações de direitos, é necessário, inicialmente, resgatar a importância da Constituição Cidadã, ${ }^{6}$ já que foi a partir dela que se consolidou o valor da dignidade da pessoa humana em um autêntico Estado Democrático de Direito. Vale lembrar, assim, o artigo $1^{\circ}$ da Carta Maior, quando estabelece, ao lado da soberania, da cidadania, dos valores sociais do trabalho e da livre iniciativa e do pluralismo político, a valor da dignidade humana como um dos princípios fundamentais do ordenamento jurídico do Brasil, princípio sem o qual sequer poderia se falar em Constituição. De acordo com Sarlet (2007),

Temos por dignidade da pessoa humana a qualidade intrínseca e distintiva de cada ser humano que o faz merecedor do mesmo respeito e consideração por parte do Estado e da comunidade, implicando, neste sentido, um complexo de direitos e deveres fundamentais que asseguram a pessoa tanto contra todo e qualquer ato de cunho degradante e desumano, como venham a lhe garantir as condições existenciais mínimas para uma vida saudável, além de propiciar e promover sua participação ativa e co-responsável nos destinos da própria existência e da vida em comunhão com os demais seres humanos. (SARLET, 2007, p.62)

Em discurso proferido por ocasião das comemorações dos 30 anos da Constituição de 1988, o ministro do STF, Marco Aurélio Mello, argumentou que esse modelo constitucional que predomina nas democracias ocidentais traz os direitos fundamentais como centro de gravidade.

Após os horrores do nazismo, passou-se a apostar na capacidade de a Constituição conformar o social, considerada a ordem e a realidade. A Constituição, tendo os direitos fundamentais no centro, seria dotada de vontade e força normativas, isso porque passou a ser, sem idealismos nem pessimismos realistas, mas combinando forma e matéria, a ordem fundamental e jurídica da coletividade (...) Ao lado da estruturação do poder e da limitação diante da soberania popular, o constituinte deu especial ênfase à disciplina dos direitos fundamentais, todos gravitando em torno da dignidade da pessoa humana. (MELLO, 2018, p. 4)

\footnotetext{
${ }^{6}$ Em 2018 completaram-se 30 anos de promulgação da Constituição de 1988, o que coloca a questão se o momento foi de comemoração ou de preocupação diante dos recentes retrocessos no campo dos direitos humanos e sociais. Como argumentam Almeida Neto e Siqueira (2017, p. 9), "em tempos de ameaça aos direitos sociais e trabalbistas, de intolerância e violência contra a mulher, de homofobia e de racismo, de ondas de conservadorismo e de ameaças a direitos indígenas, de conclamas à ditadura militar, de fragmentação das demandas e das lutas sociais, falar em Direitos Humanos tornou-se um desatino. Tidos por inevitáveis e hegemônicos, os discursos do desarranjo nos poucos direitos sociais e das concepções privatistas fazem as vozes contrárias a esses modelos soarem anacrônicas".
} 
Nessa mesma linha de pensamento, Adorno (2010) registra que os direitos humanos constituem a espinha dorsal da Constituição de 1988.

Ela [Constituição de 1988] afirma que a República Federativa do Brasil constitui um Estado Democrático de Direito, fundado, além da soberania e da cidadania, na dignidade da pessoa humana e no pluralismo político. Sob o ponto de vista das relações internacionais, orienta-se por inúmeros preceitos inscritos na Declaração Universal de 1948. (ADORNO, 2010, p.8-9)

Constata-se, portanto, que a própria Constituição de 1988 foi resultado de um processo histórico nacional de lutas e conquistas de direitos, ao mesmo tempo em que refletiu os tratados internacionais de direitos humanos. Contudo, ainda que compreendida em termos de sua "força normativa", a Carta de 1988 não foi suficiente para implementar os direitos humanos no Brasil. Daí a importância das três versões do Programa Nacional de Direitos Humanos, que devem ser entendidos, inicialmente, em termos da continuidade entre eles, ou seja:

Uma breve comparação entre os PNDHs reforça ainda mais as linhas de continuidade. As três edições têm características comuns. Em primeiro lugar, sua natureza suprapartidária. Como aponta a literatura especializada, cada vez mais o respeito, a proteção e a promoção dos direitos humanos têm se convertido em requisito para consolidação das instituições democráticas (...) Em segundo lugar, os programas pretendem enfrentar a desarticulação entre instâncias decisórias do aparato de Estado e de governo bem como entre governantes e governados, representados na esfera civil pelas organizações não governamentais (...) Por fim, todas elas resultam de consultas à sociedade civil, em praticamente todo o território nacional, seja sob a forma de seminário para acolhimento de propostas e sugestões (PNDH-1), seja sob a forma de Conferências Nacionais de Direitos Humanos (como nos PNDH 2 e 3). (ADORNO, 2010, p. 10)

O Brasil foi um dos primeiros países a atender a principal recomendação da Conferência Mundial dos Direitos Humanos de Viena (1993), lançando em 1996a primeira versão do PNDH que, por razões óbvias, deu ênfase aos direitos civis e políticos. O PNDH-1 foi estruturado com basicamente três conjuntos de direitos: proteção do direito à vida, à liberdade e ao tratamento igualitário perante a lei, além de abordar a educação para os direitos humanos e sinalizar para a necessidade de ratificação de convenções internacionais. Apesar das críticas pelo silêncio em relação a vários temas caros aos direitos humanos, a primeira versão do PNDH deve ser reconhecida menos pelo alcance das propostas e mais pela tradução de um conjunto de princípios constitucionais para uma linguagem própria e mais compreensiva do significado dos direitos humanos.

Alguns anos após, ainda durante o Governo FCH, ampliou-se as ações do PNDH em resposta, sobretudo, às críticas e reivindicações de vários segmentos sociais bem como em atendimento às novas recomendações da IV Conferência Nacional dos Direitos Humanos, realizada em 1999. Lançado em 2002, o PNDH-27teve como principal característica incorpo-

7 O PNDH-2 contou com um total de 518 propostas distribuídas entre as garantias do direito à vida, à justiça, à liberdade, à igualdade, à educação, à saúde, ao trabalho, à moradia, ao meio ambiente saudável, à alimentação, à cultura e ao lazer. As inovações em relação aos segmentos atendidos se deram pela incorporação dos direitos de livre orientação sexual e identidade de gênero, além da proteção dos ciganos, anteriormente não contemplados pelo programa. Conferiu, ainda, "maior ênfase à violência intrafamiliar, o combate ao trabalho infantil e ao trabalho forçado, bem como à luta para inclusão dos 
rar os direitos econômicos, sociais e culturais, conforme o próprio texto em sua introdução apresenta:

Sem abdicar de uma compreensão integral e indissociável dos direitos humanos, o programa original conferiu maior ênfase à garantia de proteção dos direitos civis. O processo de revisão do PNDH constitui um novo marco na promoção e proteção dos direitos humanos no País, ao elevar os direitos econômicos, sociais e culturais ao mesmo patamar de importância dos direitos civis e políticos.

Finalmente, a terceira e última versão do PNDH foi lançada em 2009, e embora também tenha surgido no sentido de revisão e ampliação dos programas anteriores, incorporou novas e polêmicas temáticas, bem como novos sujeitos de direito. ${ }^{8} \mathrm{O}$ PNDH-3 se estruturou em seis eixos orientadores. O primeiro eixo, "Interação Democrática entre Estado e Sociedade Civil", propõe integração e aprimoramento dos fóruns de participação existentes e a criação de novos espaços e mecanismos institucionais de interação e acompanhamento. Também reafirma o compromisso com a participação direta da população através de conselhos, fóruns etc.

O segundo eixo, "Desenvolvimento e Direitos Humanos", foca nas políticas de inclusão social com estratégias de desenvolvimento local e territorial, fortalecimento da agricultura familiar, incentivo à economia solidária, cooperativismo e pequenos empreendimentos. Prevê, ainda, políticas voltadas à proteção do meio ambiente e investimento em tecnologias sociais e inclusivas como forma de assegurar direitos fundamentais para as gerações presentes e futuras.

O terceiro eixo, "Universalizar Direitos em um Contexto de Desigualdades", buscou complementar os eixos anteriores no sentido de reduzir a pobreza e garantir geração de renda aos segmentos sociais mais pobres. Envolveu especialmente as políticas voltadas à erradicação da fome e da miséria.

O quarto eixo, "Segurança Pública, Acesso à Justiça e Combate à Violência", tratou do abuso da violência policial e estabeleceu metas para diminuir a violência sexual, a erradicação do tráfico de pessoas e da tortura, reformulação do sistema de justiça e segurança pública, acesso universal à justiça, disponibilização de informações e fortalecimento dos modelos alternativos de resolução de conflitos.

O quinto eixo, "Educação e Cultura em Direitos Humanos", volta-se para um conjunto de propostas, via processos de educação e de cultura, visando a formação de consciência voltada para o respeito, a tolerância, a solidariedade e o compromisso contra as variadas formas de discriminação, opressão e violência. ${ }^{9}$

cidadãos que demandam cuidados especiais" (ADORNO, 2010, p. 12). Destacam-se, também, as propostas relativas aos afrodescendentes, na medida em que reconhece pela primeira vez a existência do racismo e aponta para a necessidade de políticas de ações afirmativas voltadas para esse segmento.

8 O PNDH-3 incorporou não apenas os resultados da $11^{\text {a }}$. Conferência Nacional de Direitos Humanos, mas também as propostas de mais de 50 conferências nacionais temáticas realizadas no período de 2003 a 2009, tais como: segurança alimentar, educação, saúde, LGBT, habitação, igualdade racial, direitos da mulher, juventude, crianças e adolescentes, pessoas com deficiência, idosos, meio ambiente. O PNDH-3 optou pela metodologia de guiar as discussões das conferências em seis eixos orientadores, subdivididos em 24 diretrizes, 82 objetivos estratégicos e 521 ações programáticas.

${ }^{9}$ No que refere à educação em direitos humanos, cabe destacar a criação em 2003, no âmbito do PNDH-2, do Plano Nacional de Educação em Direitos Humanos, estruturado em cinco eixos: Educação Básica, Ensino Superior, Educação NãoFormal, Educação dos Profissionais Sistemas de Justiça e Segurança, e Educação e Mídia. E em 2012 foi aprovada, pelo Conselho Nacional de Educação (CNE), as Diretrizes Nacionais para a Educação em Direitos Humanos. 
Finalmente, o sexto e último eixo refere-se ao "Direito à Memória e à Verdade", e parte da concepção de que a memória histórica é um componente fundamental na construção da identidade social e cultural de um povo/nação, além de contribuir para a garantia da não repetição de violações de direitos humanos em períodos de exceção.

Como afirmado anteriormente,embora se reconheça o caráter de continuidade entre as três versões do PNDH, a reação quase imediata ao PNDH-3, bem como o recuo do governo à época em algumas das propostas apresentadas, indica a forte resistência a essa versão. Depois de uma década do lançamento do PNDH-3, pode se constatar que as resistências não se limitaram àquele momento, mas permaneceram e até mesmo se ampliaram. Embora seja possível observar retrocessos e violações de direitos humanos em todos os eixos propostos pelo PNDH-3, nesse artigo nos concentramos na análise do segundo eixo relativo à concepção de desenvolvimento à luz dos direitos humanos. Antes, contudo, apresentaremos breves comentários sobre o Decreto 7.177, de 12/05/2010, que alterou a proposta original do PNDH-3, como forma de avaliarmos em que medida as resistências iniciais se ampliaram e passaram a eleger os direitos humanos como alvo preferencial das políticas e das mentalidades conservadoras, autoritárias e fundamentalistas, não apenas no âmbito dos direitos civis, políticos e sociais, mas também no âmbito dos direitos culturais e ambientais, considerados em suas interconexões com as dimensões anteriores.

\section{AS PRIMEIRAS RESISTÊNCIAS AO PNDH-3 E COMO ELAS SE AM- PLIARAM NOS ÚLTIMOS 10 ANOS}

As primeiras análises sobre o PNDH-3 já indicavam, à época de seu lançamento, os temas de maior resistência. Pode-se dizer que parte das críticas teve origem na ignorância de quem não o leu, ou no desconhecimento da importância daquilo que Comparato (1999) caracteriza como a "afirmação histórica dos direitos humanos".Para Pertence (2010), somavam-se a essa ignorância as resistências advindas de instituições como a Igreja Católica, acerca da descriminalização do aborto e outras pautas de costumes, das Forças Armadas, na referência à Lei de Anistia de 1979, e das grandes empresas de comunicação, no que se refere à proposta de controle social da mídia. Nos pontos em que a reação se fundava nos preconceitos, segundo o autor, a evolução cultural deveria superá-los, desde que preservada e ampliada a liberdade de expressão. Mais árdua seria a caminhada, segundo ele, para vencer os interesses, por exemplo, das grandes empresas de comunicação.

Nesse sentido, entre os pontos mais polêmicos que repercutiram em reações imediatas após o lançamento do PNDH-3, e que foram amplamente difundidos, estão a criação da Comissão Nacional da Verdade, a descriminalização do aborto, a criação de um ranking dos veículos de comunicação, o impedimento de ostentação de símbolos religiosos em órgãos públicos, o apoio à união civil de pessoas do mesmo sexo, com direito à adoção e inclusão nos sistemas de informação, entre outros. Nessa breve reflexão, trataremos de apenas alguns desses temas, com o intuito apenas de demonstrar os primeiros contornos dessa resistência inicial ao texto do PNDH-3.

Ressalta-se, inicialmente, que de todos esses pontos o relativo à união civil homo afetiva talvez seja o que mais obteve avanços do ponto de vista jurídico, ${ }^{10}$ já que o Supremo Tribu-

10 Apesar desses avanços, outras pautas do PNDH-3 sofreram retrocessos, como a decisão do julgamento, em setembro de 2017, da Ação Direta de Inconstitucionalidade (ADI) 4439 sobre o caráter confessional do oferecimento do Ensino Reli-

PRACS: Revista Eletrônica de Humanidades do Curso de Ciências Sociais da UNIFAP 
nal Federal reconheceu por unanimidade, em 2011, a união estável entre pessoas do mesmo sexo. ${ }^{11}$ Mais recentemente, em junho de 2019, o STF também julgou procedente a criminalização da homotransfobia, fundamentado, entre outros, no inciso XLI do art. $5^{\circ}$ da Constituição Federal de 1988. ${ }^{12}$ Tais avanços, contudo, não diminuíram o preconceito, haja vista a ampliação da intolerância contra a população LGBT, nem reduziram os índices de violência, considerando que o Brasil ainda ocupa o primeiro lugar no ranking dos países onde mais de matam pessoas LGBT no mundo. ${ }^{13}$

Em relação aos outros temas que constaram na versão original do PNDH-3 e que foram objeto de resistência e alterações, registra-se, inicialmente, duas ações programáticas que foram revogadas: a ação que propunha elaborar "critérios de acompanhamento editorial a fim de criar um ranking nacional de veículos de comunicação comprometidos com os princípios de Direitos Humanos", e a ação que propôs "desenvolver mecanismos para impedir ostentação de símbolos religiosos em estabelecimentos público da União”.

No que se refere à descriminalização do aborto, a ação que propunha "apoiar a aprovação do projeto de lei que descriminaliza o aborto, considerando a autonomia das mulheres para decidir sobre seus corpos", foi alterada nos seguintes termos: "considerar o aborto como tema de saúde pública, com a garantia do acesso aos serviços de saúde". Embora a polêmica com a Igreja Católica já existisse por ocasião do PNDH-2, que também considerou o aborto um problema de saúde pública, no PNDH-3 o tema é inserido, originalmente, nas garantias dos direitos das mulheres para decidir, ou seja, deslocando a questão da esfera pública para a esfera da liberdade individual e subjetiva. Com a alteração pelo Decreto 7.177/2010, voltouse a considerar o aborto um problema de saúde pública. Considerando as diversas iniciativas no âmbito do Legislativo e do Executivo acerca das questões de gênero, especialmente no que se refere aos direitos das mulheres, não seria improvável que a temática do aborto retornasse ao estágio inicial da pura e simples criminalização das mulheres, ainda que tal matéria

gioso. A decisão, bastante disputada (6 x 5), considerou que o Ensino Religioso confessional não viola a laicidade do Estado e da educação, o que destoa de interpretações de especialistas no tema. Este panorama ratifica a afirmação de Cunha (2013, p. 11), qual seja, "enquanto a discussão da legislação sobre direitos sexuais e reprodutivos se faz em termos cada vez mais laicos, a educação pública segue permeada pela presença religiosa", ainda que o recrudescimento do conservadorismo e sua influência na política tendam a demonstrar que tais avanços possam estar em risco.

11 A decisão se refere ao julgamento da ADI 4277 e da Argüição de Descumprimento de Preceito Fundamental (ADPF) 132, ajuizadas, respectivamente, pela Procuradoria-Geral da República e pelo governador do Rio de Janeiro. O julgamento foi realizado em maio de 2011, e teve como relator o ministro Ayres Britto. Apenas o ministro Dias Toffoli não participou do julgamento porque atuou em uma das ações enquanto era advogado-geral da União.

12 Depois de seis sessões dedicadas ao tema, oito ministros votaram favoráveis e três ministros votaram contrários à tese da criminalização da homotransfobia, equiparando a discriminação de pessoas LGBT à discriminação por racismo, essa já prevista em legislação federal. Tal decisão, contudo, terá validade até que o Congresso legisle sobre o tema. Ressalta-se, ainda, que houve dez votos favoráveis ao reconhecimento da omissão legislativa sobre a matéria. Portanto, por ampla maioria, o STF julgou procedente a ação relativa à criminalização da homotransfobia, com eficácia geral e efeito vinculante, reconhecendo o estado de mora inconstitucional do Congresso Nacional na implementação da prestação legislativa destinada a cumprir o mandado de incriminação a que se referem os incisos XLI e XLII do art. $5^{\circ}$ da CF/1988.

${ }^{13}$ Em relatório sobre violação de direitos humanos, divulgado em janeiro de 2018, a organização internacional Human Rights aponta que a Ouvidoria Nacional dos Direitos Humanos recebeu, apenas no primeiro semestre de 2017, 725 denúncias de violência, discriminação e outros abusos contra a população LGBT. E de acordo com dados divulgados pela Associação Nacional de Travestis e Transexuais (ANTRA), 179 transexuais foram assassinados no Brasil em 2017, reduzindo a expectativa de uma pessoa transexual no País a 35 anos, o que corresponde à metade da média nacional. Também de acordo com matéria de "O Globo" em 14/11/2018, intitulada "Brasil segue no primeiro lugar do ranking de assassinatos de transexuais", dados da ONG Transgender Europe (TGEU) apontam que entre 01/10/2016 a 30/09/2017 167 transexuais foram mortos no Brasil. Fonte: https://glo.bo/2WDEwMo (acesso em 10 de junho de 2019). 
também esteja tramitando no STF. ${ }^{14}$

Sobre o suposto "controle" dos meios de comunicação, além da revogação da ação mencionada anteriormente, houve alteração na ação que propunha "promover o respeito aos direitos humanos nos meios de comunicação e o cumprimento de seu papel na promoção da cultura em direitos humanos". ${ }^{15}$ Observa-se,nesse caso, a subtração da segunda parte do texto original, na qual se previa o respeito aos direitos humanos como condição para "sua outorga e renovação", bem como a previsão de penalidades "de acordo com a gravidade das violações praticadas". Ou seja,mesmo mantendo o "respeito aos direitos humanos", subtraiu-se do novo texto qualquer possibilidade de penalidade por violações desses direitos. Uma breve reflexão sobre o papel da grande mídia no contexto político, em especial na forma como a cobertura jornalística pode parecer filiada a um ou outro dos segmentos em disputa, bem como pela aparente seletividade acerca das notícias e suas personagens, sugere a complexidade desse tema e os desafios para se avançar no sentido de garantir a liberdade de imprensa sem violação de direitos e garantias fundamentais previstos na Constituição de 1988.

Não por acaso, e à luz de um contexto no qual se observa, inclusive, manifestações públicas por "intervenção militar", não é irrelevante registrar que as temáticas relativas ao "direito à memória e à verdade"já se constituíam, à época do lançamento do PNDH-3, em tema relevante e polêmico. Com efeito, essa temática foi a que mais resultou em alterações à versão original. No que se refere à preservação da memória histórica sobre períodos de exceção, duas ações foram alteradas. A primeira inclui apalavra "circunstâncias" e substitui a palavra "perseguidos" por "desaparecidos". ${ }^{16}$ A segunda substitui a frase "regime de 1964-1985" por "período fixado no art. $8^{\circ}$ do Ato das Disposições Constitucionais Transitórias da Constituição de 1988”. Ainda nessa ação programática, retira-se a expressão "resistência popular à repressão", deixando evidenciadas as diferenças de visão nesse caso. ${ }^{17}$

Ainda sobre a temática do "direito à memória e à verdade", outras duas alterações foram realizadas: substituição da proposta de legislação que proíbe que criminosos de lesahumanidade tenham seus nomes identificados em espaços públicos, pela proposta de "fomentar debates e divulgar informações". ${ }^{18} \mathrm{E}$ a subtração das palavras "responsabilização

14 Trata-se da Ação de Descumprimento de Preceito Fundamental (ADPF) no 442, que visa descriminalizar mulheres que façam a interrupção voluntária da gestação até a $12^{\mathrm{a}}$ semana da gravidez. Caso o julgamento acolha a ação, a equipe médica envolvida no procedimento também não poderá ser punida. A ministra Rosa Weber, relatora da ação, realizou audiência pública em agosto de 2018, mas não tem prazo para apresentar seu parecer, que depois deverá ir a julgamento do plenário.

15 Texto original: "propor criação de marco legal regulamentando o artigo 221 da Constituição, estabelecendo o respeito aos direitos humanos nos serviços de radiodifusão (rádio e televisão) concedidos, permitidos ou autorizados, como condição para sua outorga e renovação, prevendo penalidades administrativas como advertência, multa, suspensão da programação e cassação, de acordo com a gravidade das violações praticadas". Texto alterado: "propor a criação de marco legal, nos termos do art. 221 da Constituição, estabelecendo o respeito aos direitos humanos nos serviços de radiodifusão (rádio e televisão) concedidos, permitidos ou autorizados".

16 Texto original: "identificar e sinalizar locais públicos que serviram à repressão ditatorial, bem como locais onde foram ocultados corpos e restos mortais de perseguidos políticos". Texto alterado: "identificar e tornar públicos as estruturas, os locais, as instituições e as circunstâncias relacionadas à prática de violações de direitos humanos, suas eventuais ramificações nos diversos aparelhos estatais e na sociedade, bem como promover, com base no acesso às informações, os meios e recursos necessários para a localização e identificação de corpos e restos mortais de desaparecidos políticos".

17 Texto original: “desenvolver programas e ações educativas, inclusive a produção de material didático-pedagógico para ser utilizado pelos sistemas de educação básica e superior sobre o regime de 1964-1985 e sobre a resistência popular à repressão". Texto alterado: "desenvolver programas e ações educativas, inclusive a produção de material didáticopedagógico para ser utilizado pelos sistemas de educação básica e superior sobre graves violações de direitos humanos ocorridas no período fixado no art. $8^{\circ}$ do Ato das Disposições Constitucionais Transitórias da Constituição de 1988”.

18 Texto original: "propor legislação de abrangência nacional proibindo que logradouros, atos e próprios nacionais e pré-

PRACS: Revista Eletrônica de Humanidades do Curso de Ciências Sociais da UNIFAP https://periodicos.unifap.br/index.php/pracs ISSN 1984-4352 Macapá, v. 12, n. 3, p. 33-50, dez. 2019 
criminal" dos processos judiciais, sugerindo o não reconhecimento da existência de crimes durante o referido regime. ${ }^{19}$

Mesmo com tais polêmicas e alterações no texto original do PNDH-3, o fato é que em 2012 a "Comissão Nacional da Verdade" foi instalada, e em 2014 seu "Relatório Final" foi lançado com 29 recomendações, responsabilizando 377 pessoas por crimes durante a repressão e registrando 434 mortos e desaparecidos. Entre as principais conclusões do referido relatório, destaca-se aquela que aponta para o fato de que a falta de investigação e de punição aos violadores de direitos humanos representa um dos fatores que levam à sua "perpetuação" no Brasil, ou seja,

Embora não ocorra mais em um contexto de repressão política - como ocorreu na ditadura militar -, a prática de detenções ilegais e arbitrárias, tortura, execuções, desaparecimentos forçados e mesmo ocultação de cadáveres não é estranha à realidade brasileira contemporânea [...] Esse quadro resulta em grande parte do fato de que o cometimento de graves violações de direitos humanos verificado no passado não foi adequadamente denunciado, nem seus autores responsabilizados, criando-se as condições para sua perpetuação (Relatório da Comissão Nacional da Verdade, 2014).

Se considerarmos o cenário de polarização política e ideológica que resultou, em 2018, na eleição deum ex-militar cuja trajetória política nas ultimas três décadas foi marcada pela defesa do regime militar e pelo culto à memória de pessoas identificadas com a prática da tortura, as reflexões decorrentes do PNDH-3, bem como dos trabalhos e das conclusões da Comissão Nacional da Verdade, tornam-se ainda mais relevantes. Ou seja, 10 anos após essas questões terem sido marcadas por fervoroso debate público, e diante de declarações recentes no sentido da necessidade de um novo AI-5 para conter manifestações populares, até que ponto se pode considerar que, no Brasil, o paradigma dos direitos humanos tem sido cada vez mais substituído pela narrativa dos "humanos direitos", com todos os riscos e contradições que essa narrativa pode suscitar no contexto de um Estado Democrático e Constitucional de Direito.

As reflexões até aqui apresentadas sinalizam, sobretudo, os desafios à implementação do que foi originalmente pretendido pelo PNDH-3 em suas múltiplas dimensões. O próximo tópico visa discutir, passados 10 anos de seu lançamento, o conteúdo específico acerca do tema desenvolvimento e direitos humanos, mais precisamente os desafios que se apresentam em um contexto sócio-político avesso às perspectivas calcadas na concepção de desenvolvimento com respeito e garantia à dignidade da pessoa humana.

\section{DESENVOLVIMENTO E DIREITOS HUMANOS: ANÁliSE A PAR- TIR DO EIXO II DO PNDH-3}

dios públicos recebam nomes de pessoas que praticaram crimes de lesa-humanidade, bem como determinar a alteração de nomes que já tenham sido atribuídos". Texto alterado: "fomentar debates e divulgar informações no sentido de que logradouros, atos e próprios nacionais ou prédios públicos não recebam nomes de pessoas identificadas reconhecidamente como torturadores".

19 Texto original: “acompanhar e monitorar a tramitação judicial dos processos de responsabilização civil ou criminal sobre casos que envolvam atos relativos ao regime de 1964-1985”. Texto alterado: "acompanhar e monitorar a tramitação judicial dos processos de responsabilização civil sobre casos que envolvam graves violações de direitos humanos praticadas no período fixado no art. $8^{\circ}$ do Ato das Disposições Constitucionais Transitórias Constituição 1988”. 
O Eixo Orientador II do PNDH-3, "Desenvolvimento e Direitos Humanos" (EOIIDDH), visa promovera noção de desenvolvimento em confluência com uma perspectiva de direitos humanos que garanta "[...] a livre determinação dos povos, o reconhecimento de soberania sobre seus recursos e riquezas naturais, respeito pleno à sua identidade cultural e a busca de equidade na distribuição das riquezas". Ainda de acordo com o PNDH-3, o desenvolvimento econômico deve ser entendido como "um processo que faz aumentar as possibilidades de acesso das pessoas a bens e serviços, propiciadas pela expansão da capacidade e do âmbito das atividades econômicas".

Um dos autores de referência do PNDH-3 para o conceito de desenvolvimento é Amartya Sen, professor de economia e filosofia da Universidade de Harvard, segundo o qual desenvolvimento e liberdade precisam ser entendidos inextricavelmente, evitando, assim, visões muito restritas. Segundo o autor, para que haja desenvolvimento algumas privações de liberdade precisam ser removidas, tais como "pobreza e tirania, carência de oportunidades econômicas e destituição social sistemática, negligência dos serviços públicos e intolerância ou interferência excessiva de Estados repressivos" (SEM, 2000, p. 18). Assim, para o autor, a liberdade ocupa a centralidade do desenvolvimento uma vez que é condição para a avaliação do progresso e a garantia da livre condição de agência das pessoas.

Nesse sentido, Sen (2000, p. 25) apresenta cinco tipos de "liberdades instrumentais", quais sejam: (1) liberdades políticas, (2) facilidades econômicas, (3) oportunidades sociais, (4)garantias de transparência e (5) segurança protetora, estas que, "na visão do 'desenvolvimento como liberdade', [...] ligam-se umas às outras e contribuem com o aumento da liberdade humana em geral". Tal abordagem, portanto, embasa as políticas de desenvolvimento no PNDH-3, o que justifica a afirmação no documento de que "são essenciais para o desenvolvimento as liberdades e os direitos básicos como alimentação, saúde e educação”. O texto introdutório também discute como o Produto Interno Bruto (PIB) tornou-se obsoleto para medir o avanço dos países no atendimento das necessidades da população, e por isso tanto o conceito de desenvolvimento quanto o índice de Desenvolvimento Humano (IDH) substituíram o PIB como mensuração, evitando avaliações que se limitavam a padrões econométricos.

Ainda no texto introdutório do PNDH-3, afirma-se que o Brasil apresenta elevados índices de desigualdade, o que requer políticas de longa duração para proteção e promoção dos Direitos Humanos. É indicada a necessidade do protagonismo das pessoas como garantia do desenvolvimento, na busca de direitos que objetivem "[...] a distribuição da riqueza, dos bens e serviços". Pretende-se, desta forma, refletir acerca dos paradigmas de desenvolvimento levados como política econômica e social dos governos, bem como suas limitações, em especial em como estas abordagens compreendem o meio ambiente e os sistemas produtivos implantados. Neste sentido, o PNDH-3 visa, a partir da perspectiva dos direitos humanos, redimensionar a ideia de desenvolvimento, tratando os problemas individuais como temas de interesse comum, que diz respeito ao bom convívio social, além de atribuir ao Estado a responsabilidade de enfrentar estes desafios.

O EOII-DDH é composto por 3 diretrizes (12,5\% do total de diretrizes), 8 objetivos estratégicos (9,7\% do total de objetivos estratégicos) e 57 ações programáticas $(10,9 \%$ do total de ações programáticas). Com o intuito de apresentar a forma como esse Eixo foi organizado em termos da distribuição quantitativa das ações programáticas, bem como das temáticas propostas para o desenvolvimento com direitos humanos, sintetizamos no quadro 1 algumas

PRACS: Revista Eletrônica de Humanidades do Curso de Ciências Sociais da UNIFAP 
dessas informações:

Quadro 1 - Eixo Orientador II: Desenvolvimento e Direitos Humanos por diretriz, objetivo estratégico (OE) e quantidade de ações programáticas (AP)

\begin{tabular}{|l|c|}
\hline $\begin{array}{l}\text { Diretriz 4: Efetivação de modelo de desenvolvimento sustentável, com inclusão social e econô- } \\
\text { mica, ambientalmente equilibrado e tecnologicamente responsável, cultural e regionalmente } \\
\text { diverso, participativo e não discriminatório }\end{array}$ & AP (n⿳) \\
\hline OE I. Implementação de políticas públicas de desenvolvimento com inclusão social & 13 \\
\hline OE II. Fortalecimento de modelos de agricultura familiar e agroecológica & 5 \\
\hline $\begin{array}{l}\text { OE III. Fomento à pesquisa e à implementação de políticas para o desenvolvimento de tecnologias soci- } \\
\text { almente inclusivas, emancipatórias e ambientalmente sustentáveis }\end{array}$ & 6 \\
\hline OE IV. Garantia do direito a cidades inclusivas e sustentáveis & 9 \\
\hline Diretriz 5: Valorização da pessoa humana como sujeito central do processo de desenvolvimento & - \\
\hline $\begin{array}{l}\text { OE I. Garantia da participação e do controle social nas políticas públicas de desenvolvimento com grande } \\
\text { impacto socioambiental }\end{array}$ & 8 \\
\hline $\begin{array}{l}\text { OE II. Afirmação dos princípios da dignidade humana e da equidade como fundamentos do processo de } \\
\text { desenvolvimento nacional }\end{array}$ & 5 \\
\hline $\begin{array}{l}\text { OE III. Fortalecimento dos direitos econômicos por meio de políticas públicas de defesa da concorrência } \\
\text { e de proteção do consumidor }\end{array}$ & 4 \\
\hline $\begin{array}{l}\text { Diretriz 6: Promover e proteger os direitos ambientais como Direitos Humanos, incluindo as } \\
\text { gerações futuras como sujeitos de direitos }\end{array}$ & - \\
\hline OE I. Afirmação dos direitos ambientais como Direitos Humanos & 7 \\
\hline
\end{tabular}
Fonte: PNDH-3, organizado pelos autores (2019).

O que foi estabelecido como objetivos estratégicos nas diretrizes que compõem o EOIIDDH coaduna com seu texto de introdução, isto é, a participação popular e do Estado no combate às desigualdades e a busca pela dignidade da pessoa humana, que embasa as ações programáticas. As políticas públicas são acionadas como condição para que o Estado possa agir, em consonância com decisões calcadas na participação das comunidades interessadas. Nota-se, também, a atenção que se remete a uma concepção de meio ambiente em sintonia com os direitos humanos, compreendendo a natureza não como um espaço alheio à humanidade e com recursos naturais ilimitados. Ao contrário, como proposto com mais detalhes na Diretriz 6, o meio ambiente é lido a partir da sua fragilidade em face da exploração capitalista no decorrer da história, buscando a harmonia entre meio ambiente e dignidade da pessoa humana.

Tendo como referência as recomendações acima referidas, e observando o contexto mais recente, registra-se que a criação, alteração ou extinção de secretarias e ministérios nos últimos dois governos afetam direta e indiretamente as proposituras originais constantes no PNDH-3. Vale lembrar que o governo que iniciou em 2019promoveu grandes mudanças na estrutura ministerial e de secretarias, primeiramente por meio da Medida Provisória $\mathrm{n}^{\circ} 870$ de $1^{\circ}$ de janeiro de 2019, e depois convertida na Lei $\mathrm{n}^{\circ} 13.844$, de 18 de junho do mesmo ano. ${ }^{20} \mathrm{O}$ Quadro 2 apresenta a forma como as ações programáticas foram distribuídas no EOII-DDH, em termos da responsabilidade de secretarias e ministérios, e qual é a situação atual desses órgãos estatais. ${ }^{21}$

${ }^{20} \mathrm{Nem}$ todas as mudanças de órgãos, secretarias e ministérios foram realizadas no atual governo: um conjunto de mudanças também ocorreu nos governos de Dilma Rousseff e Michel Temer, ainda que as alterações tenham sido menores se comparado com o que foi estabelecido em 2019.

21 Os órgãos responsáveis pelas ações programáticas do EOII-DDH são os seguintes: Ministério da Agricultura, Pecuária e Abastecimento (MAPA), Ministério da Cultura (MinC), Ministério da Educação (MEC), Ministério da Fazenda (MF), Ministério da Integração Nacional (MI), Ministério da Justiça (MJ), Ministério da Pesca e Aquicultura (MPA), Ministério da Saúde (MS), Ministério das Cidades (MCidades), Ministério da Ciência e Tecnologia (MCTIC), Ministério de Minas e 
Quadro 2 - Distribuição da responsabilidade dos Ministérios e Secretarias no Eixo Orientador II: Desenvolvimento e Direitos Humanos

\begin{tabular}{|c|c|c|c|c|c|c|c|c|c|c|}
\hline \multirow{3}{*}{$\begin{array}{l}\text { Ministérios e } \\
\text { Secretarias }\end{array}$} & \multirow{3}{*}{ Situação } & \multicolumn{9}{|c|}{$\begin{array}{l}\text { Responsável, por números de ações programáticas, definidos nos objetivos estra- } \\
\text { tégicos das Diretrizes } 4,5 \text { e } 6\end{array}$} \\
\hline & & \multicolumn{4}{|c|}{ Diretriz 4} & \multicolumn{3}{|c|}{ Diretriz 5} & \multirow{2}{*}{$\begin{array}{c}\text { Diretriz } 6 \\
\text { OE } \\
1\end{array}$} & \multirow{2}{*}{$\begin{array}{c}\text { Total } \\
8 \text { Objetivos } \\
\text { Estratégicos }\end{array}$} \\
\hline & & $\begin{array}{c}\mathrm{OE} \\
1\end{array}$ & $\begin{array}{c}\mathrm{OE} \\
2\end{array}$ & $\begin{array}{c}\mathrm{OE} \\
3\end{array}$ & $\begin{array}{c}\mathrm{OE} \\
4\end{array}$ & $\begin{array}{c}\mathrm{OE} \\
1\end{array}$ & $\begin{array}{c}\mathrm{OE} \\
2\end{array}$ & $\begin{array}{c}\mathrm{OE} \\
3\end{array}$ & & \\
\hline MAPA & Vigente & 0 & 2 & 2 & 1 & 0 & 0 & 1 & 0 & 6 \\
\hline MinC & Extinto & 1 & 0 & 0 & 0 & 0 & 0 & 0 & 0 & 1 \\
\hline MEC & Vigente & 0 & 1 & 0 & 0 & 0 & 0 & 1 & 0 & 2 \\
\hline MF & Extinto & 0 & 0 & 0 & 0 & 0 & 1 & 1 & 0 & 2 \\
\hline MI & Extinto & 2 & 0 & 1 & 0 & 2 & 0 & 0 & 0 & 5 \\
\hline MJ & Vigente & 2 & 0 & 0 & 0 & 0 & 0 & 3 & 0 & 5 \\
\hline MPA & Extinto & 3 & 2 & 0 & 1 & 0 & 0 & 0 & 0 & 6 \\
\hline MS & Vigente & 0 & 1 & 5 & 1 & 2 & 0 & 1 & 0 & 10 \\
\hline MCidades & Extinto & 2 & 0 & 1 & 8 & 3 & 0 & 1 & 1 & 16 \\
\hline MC'TIC & Vigente & 0 & 0 & 5 & 0 & 0 & 0 & 0 & 0 & 5 \\
\hline MME & Vigente & 1 & 0 & 1 & 0 & 2 & 0 & 1 & 0 & 5 \\
\hline MDA & Extinto & 5 & 5 & 1 & 0 & 0 & 0 & 0 & 0 & 11 \\
\hline MDS & Extinto & 7 & 0 & 1 & 3 & 1 & 0 & 1 & 0 & 13 \\
\hline MDIC & Extinto & 2 & 2 & 1 & 1 & 0 & 1 & 2 & 0 & 9 \\
\hline MMA & Vigente & 3 & 2 & 6 & 3 & 5 & 0 & 0 & 7 & 26 \\
\hline MP & Extinto & 0 & 0 & 0 & 1 & 0 & 2 & 0 & 0 & 3 \\
\hline MTE & Extinto & 4 & 0 & 1 & 2 & 1 & 0 & 0 & 1 & 9 \\
\hline MTur & Vigente & 2 & 0 & 0 & 0 & 0 & 0 & 0 & 0 & 2 \\
\hline MTPA & Extinto & 1 & 0 & 0 & 0 & 1 & 0 & 0 & 0 & 2 \\
\hline $\mathrm{SAE} / \mathrm{SG} / \mathrm{PR}$ & Extinto & 0 & 0 & 1 & 0 & 0 & 0 & 0 & 0 & 1 \\
\hline SRI/PR & Extinto & 0 & 0 & 0 & 1 & 0 & 0 & 0 & 0 & 1 \\
\hline RSEPPIR & Extinto & 2 & 0 & 0 & 0 & 0 & 0 & 0 & 0 & 2 \\
\hline SEP/PR & Extinto & 1 & 0 & 0 & 0 & 0 & 0 & 0 & 0 & 1 \\
\hline $\mathrm{SDH} / \mathrm{PR}$ & Extinto & 4 & 0 & 1 & 1 & 4 & 3 & 0 & 3 & 16 \\
\hline
\end{tabular}

Fonte: PNDH-3, organizado pelos autores (2019).

O eixo sobre Desenvolvimento e Direitos Humanos do PNDH-3 apresenta como responsáveis pelas ações programáticas um total de 24 órgãos, sendo 19 ministérios e 5 secretarias. Porém, a estrutura atual dos órgãos mostra que, dos 19 ministérios envolvidos, 11 foram extintos, assim como todas as secretarias. Já no que diz respeito às 57 ações programáticas, se considerarmos que mais de um órgão pode ser responsável pelas mesmas, a extinção dos ministérios e secretarias afetou 53 delas. O MCidades, MDA, MDS, MDIC, MTE e $\mathrm{SDH} / \mathrm{PR}$, embora não mais componham a estrutura do governo, apresentavam à época da elaboração do PNDH-3 grande relevância em vista do número de ações programáticas atribuídas a estes órgãos. ${ }^{22}$ Mesmo que a legislação vigente defina, no caso de alguns ministérios

Energia (MME), Ministério do Desenvolvimento Agrário (MDA), Ministério do Desenvolvimento Social e Combate à Fome (MDS), Ministério do Desenvolvimento, Indústria e Comércio Exterior (MDIC), Ministério do Meio Ambiente (MMA), Ministério do Planejamento, Orçamento e Gestão (MP), Ministério do Trabalho e Emprego (MTE), Ministério do Turismo (Mtur), Ministério dos Transportes (MTPA), Secretaria de Assuntos Estratégicos da Presidência da República (SE/SG/PR), Secretaria de Relações Institucionais da Presidência da República (SRI/PR), Secretaria Especial de Políticas de Promoção da Igualdade Racial da Presidência da República (RSEPPIR), Secretaria Especial de Portos da Presidência da República (SEP/PR), Secretaria Especial dos Direitos Humanos da Presidência da República (SDH/PR).

22 Vale lembrar que meses antes da coligação vitoriosa no pleito eleitoral de 2018, já havia sinalização de que o MTE seria extinto, o que representou, na ótica dos movimentos sociais e dos grupos de defesa dos direitos humanos, um retrocesso em termos de garantias de direitos e de desenvolvimento social. 
e secretarias extintos, quais são os órgãos agora responsáveis pelas atividades, ${ }^{23}$ a diminuição do número de ministérios altera a dinâmica do que foi definido no PNDH-3, visto que a redução do status destes órgãos pode vir a comprometer o desenvolvimento das atividades previstas.

Não obstante a redução do número de ministérios e secretarias, a criação de outros órgãos demonstra uma tendência dos rumos do atual governo em dissonância com o que fora estabelecido no PNDH-3. Um exemplo é a criação da Secretaria Especial de Desestatização, Desinvestimento e Mercados, vinculada ao Ministério da Economia, já que o objetivo de "desestatizar" e "desinvestir" destoa do que foi estabelecido na introdução do EOII-DDH sobre a atribuição de responsabilidade do Estado para promoção de políticas públicas acerca do desenvolvimento, sobretudo quando levamos em consideração o seu papel nos eixos orientadores e ações programáticas definidos.

Partindo da perspectiva de Bourdieu (2014), no sentido de que para além das concepções mais teóricas e abstratas do Estado, esse é encarnado por agentes com suas posições sociais e distintos capitais simbólico, econômico, cultural e social,é relevante destacar as ações e os discursos do atual ministro da Economia, ${ }^{24}$ na medida em que o mesmo apresenta e justifica um compêndio de ações que vão no sentido contrário do que preconiza o PNDH-3, ou seja, a defesa do "Estado mínimo", da desregulamentação da economia e do "livre mercado", 25 da privatização de empresas públicas (MARTÍNEZ-VARGAS, 2019), da diminuição acentuada do funcionalismo público e do fim de sua estabilidade, ${ }^{26}$ entre outras medidas.Para além de sua biografia como um agente do mercado financeiro (MENA, 2018), três manifestações do ministro podem ser ilustrativas para compreender sua concepção de Estado, de economia e de desenvolvimento. A primeira foi realizada em Dallas (EUA), quando se referiu a Salim Mattar, titular da Secretaria Especial de Desestatização, Desinvestimento e Mercados:

Nosso amigo Salim Mattar está aqui, ele é um bilionário brasileiro. Ele vai vender tudo o que nós temos. Do palácio presidencial à casa onde eu deveria morar. Tudo, tudo o que nós pudermos vender! [...] Vamos tentar vender a Petrobrás, tentar vender o Banco do Brasil, ou, tal-

\footnotetext{
${ }^{23}$ MinC e MDS foram vinculados ao Ministério da Cidadania; MF ao Ministério da Economia; MCidades e MI ao Ministério do Desenvolvimento Regional; MPA ao Ministério da Agricultura, Pecuária e Abastecimento; MDA foi transformado em Secretaria, esta extinta e suas atribuições assaram ao Incra; MTE ao Ministério da Economia; MTPA ao Ministério da Infraestrutura; RASEPPIR ao Ministério da Mulher, da Família e dos Direitos Humanos; já a estrutura atual não deixa evidente quais órgãos assumirão as responsabilidades do MDIC, MP, SE/SG/PR, SRI/PR, SEP/PR e SDH/PR - esta última, por suas atribuições, possivelmente está no âmbito do Ministério da Mulher, Família e Direitos Humanos.

${ }^{24}$ Registra-se que outros ministérios que compõem o primeiro escalão do governo poderiam ser citados como ilustração das ações criticadas por defensores dos direitos humanos, como o Ministério da Justiça e o projeto batizado de "pacote anticrime"; o Ministério do Meio Ambiente e a forma como tem lidado com as políticas ambientais; o Ministério da Mulher, da Família e dos Direitos Humanos e a restrição das políticas voltadas à garantia de direitos de minorias; o Ministério da Educação e a sua proposta, entre outras, do "Future-se", um programa de abertura das Universidade Federais à iniciativa privada, já rejeitado pela ampla maioria das universidades e da comunidade acadêmica.

${ }^{25}$ Em abril de 2019 o governo Bolsonaro apresentou a Medida Provisória no 881, apelidada de "MP da Liberdade Econômica", com a seguinte ementa: "Institui a Declaração de Direitos de Liberdade Econômica, estabelece garantias de livre mercado, análise de impacto regulatório, e dá outras providências". Tal proposta, que passou por tramitação e aguarda edição de decreto legislativo, foi amplamente influenciada e defendida pelo atual Ministro da Economia. A Medida provisória por ser acessada em: https://bit.ly/2CmLYCf (acesso em 7 nov. 2019).

${ }^{26}$ Ao comentar a proposta de reforma administrativa, o ministro afirmou que o servidor público poderia esperar até 10 anos para conseguir a estabilidade na função, além de reduzir de 20 a 30 carreiras no serviço público. Além disso, argumentou o seguinte: "Tem filiação partidária não é servidor, é militante. Pode ser militante, mas não pode ter estabilidade". Tal afirmação viola o que está estabelecido na Constituição Federal, que não pró́be a participação política de servidores públicos. (FERNANDES et al, 2019)
} 
vez, fazer uma fusão! Tentar unir o Banco do Brasil ao Bank of America. Eles são ótimos no mercado imobiliário, empréstimo e agronegócios [...] (CONDSEF/FENADSEF, 2019).

A segunda manifestação do ministro foi no contexto de uma entrevista concedida ao jornal Folha de São Paulo. Ao responder sobre sua proposta denominada "Carteira Verde e Amarela", que propõe diminuir direitos trabalhistas em favor de maior empregabilidade, o ministro disse que "[...] os ricos capitalizam seus recursos. Os pobres consomem tudo". (SALOMÃO, 2019)

A terceira manifestação, esta que gerou maior repercussão nacional e internacionalmente, se refere a afirmação do ministro no Fórum de Altos Executivos Brasil-EUA, ocorrido em novembro de 2019 na cidade de Washington, em que diz abertamente que não seria assustador caso alguém peça um novo AI-5. Sua fala ocorreu em virtude de um descontentamento de parcela da população brasileira em vista das mudanças que as políticas econômicas estavam produzindo e as possíveis reações advindas de mobilização popular. Conforme a palavras do ministro:

"Sejam responsáveis, pratiquem a democracia. Ou democracia é só quando o seu lado ganha? Quando o outro lado ganha, com dez meses você já chama todo mundo para quebrar a rua? Que responsabilidade é essa? Não se assustem então se alguém pedir o AI-5. Já não aconteceu uma vez? Ou foi diferente? Levando o povo para a rua para quebrar tudo. Isso é estúpido, é burro, não está à altura da nossa tradição democrática” (DIAS, 2019).

O problema de tais manifestações é que elas partem da culpabilização das pessoas comuns pelas crises econômicas, pela estagnação do desenvolvimento e pela desigualdade social e concebem, por outro lado, o "mercado" e as elites econômicas como a materialização da virtude e do "progresso", sem espaço para o dissenso entre distintos projetos econômicos e sua abertura para o debate que é inerente à democracia, pluralidade de ideias que, como se observa em sua última declaração aqui citada, pode ser respondida com autoritarismo e censura. Em outras palavras, compreende o Estado de "bem-estar social" e as políticas públicas de equidade como algo a ser combatido, e a meritocracia e os agentes econômicos como os protagonistas do desenvolvimento, concepções contrárias a ideia de desenvolvimento prevista no PNDH-3. Com efeito, a demonização do Estado e a divinização do mercado remontam ao início do século XX e foi usada, desde aquele tempo, como mecanismo de dominação social para que o Estado brasileiro servisse aos interesses das elites econômicas sem a plena participação popular nas decisões sobre as políticas públicas que serão desenvolvidas, concepção que também tem se mostrado muito potente em termos de sua influência na visão política da "classe média" e dos pobres, como afirma Souza (2017).

A análise de Dowbor a respeito da política econômica brasileira no período de 20152018oferece uma reflexão oportuna para se ter uma ideia dos impactos deste tipo de visão e da configuração do Estado a partir desses preceitos. Segundo o autor, o chamado "círculo virtuoso" da economia, que deveria atender as necessidades da população como saúde, educação, emprego e renda, e que funcionou para que fossem enfrentadas crises como a de 1929 nos Estados Unidos (New Deal), na Europa (Welfare State), na Coreia do Sul, na China e em um período no Brasil (2003-2013), está em contínuo desmantelamento se tomadas como análise as decisões econômicas a partir de 2015. O resultado é um aumento da desigualdade e uma concepção equivocada de desenvolvimento. Ou seja, 
Hoje, o Estado está vendo sua capacidade de implementar políticas públicas desmanteladas, as empresas estão se transformando em gigantescas pirâmides de poder corporativo controladas pelo sistema financeiro, e as formas organizadas de participação da sociedade, fundamentais para que o conjunto funcione, estão sendo criminalizadas. [...] O objetivo geral do desenvolvimento pode ser resumido no conceito de desenvolvimento economicamente viável, socialmente justo e ambientalmente sustentável. [...] A "narrativa" de que devemos privatizar, maximizar os lucros corporativos e recorrer ao Estado mínimo repousava na ideia de que, de posse de mais dinheiro, os ricos iriam investir mais, gerar mais produção e, portanto, mais emprego, o que geraria maior produtividade social. Hoje as corporações se apropriam de mais dinheiro, e fazem mais aplicações financeiras, que não geram nem empregos nem produtos. É a era do capital improdutivo. (DOWBOR, 2018, p. 50-51)

Dowbor (2018, p. 51) conclui que o resultado desse processo é que "[...] a absurda concentração de poder e de recursos nas mãos dos gigantes financeiros está aprofundando a concentração de renda a patrimônio, ampliando os desastres ambientais, e nos jogando a todos no marasmo planetário em que vivemos", conclusões que já poderiam ser compreendidas pelas análises econômicas sobre a desigualdade feitas por Thomas Piketty (2015) antes do início do novo milênio.

Outro tema importante que pode ser considerado em nosso balanço é o argumento usado em favor da "austeridade". Segundo Rossi e Dweck (2018, p. 83), a ideia dos defensores da austeridade se define por uma “[...] política que busca, por meio de um ajuste fiscal, preferencialmente por cortes de gastos, ajustar a economia e promover o crescimento", um "sacrifício" que seria, em tese, imposto a toda a sociedade. Porém, os autores argumentam, com base nas experiências históricas, que a austeridade gera um "[...] resultado contrário ao que se propõe", além de impor "[...] sacrifícios para a parcela mais vulnerável da população, que é a que mais sofre com o desemprego e com os cortes de gastos e transferências sociais" (2018, p. 83). Com efeito, a defesa da austeridade, munida de argumentos falaciosos, revela interesses velados da classe capitalista, “[...] uma resposta dos governos às demandas do mercado e das elites econômicas à custa de direitos sociais da população e dos acordos democráticos" (2018, p. 86). ${ }^{27}$ Por mais que a austeridade seja uma "ideia equivocada do ponto de vista social e contraproducente do ponto de vista do crescimento econômico e do equilíbrio fiscal", é essa a concepção que tem fundamentado muitas das decisões dos últimos governos no Brasil, especialmente a partir de 2015.

Portanto, ainda que o enfoque até aqui tenha sido maior aos efeitos produzidos pelo Governo Bolsonaro, mudanças significativas também ocorreram antes de 2019. No governo de Michel Temer (2016-2018),por exemplo, duas decisões do Executivo e do Legislativo podem surtir efeitos contrários ao que é proposto pelo EOII-DDH: a Emenda Constitucional $n^{\circ}$ 95/2016, que congela em até 20 anos os investimentos no âmbito dos Orçamentos Fiscal e da Seguridade Social da União com base em um novo regime fiscal (BRASIL, 2016); e a Lei no 13.467/2017, chamada de "Reforma Trabalhista", que produza precarização das garantias dos trabalhadores por meio, por exemplo, da autorização de um contrato individual para prestação de trabalho intermitente. (BRASIL, 2017)

\footnotetext{
27 Exemplo disso é a abissal desigualdade no Brasil: "seis famílias detêm mais patrimônio do que a metade mais pobre no país, e os 5\% mais ricos detêm mais do que os 95\% seguintes" (DOWBOR, 2018, p. 47). O EOII-DDH propõe a taxação de grandes fortunas dentre suas propostas. Contudo, não há indicativos de que isto seja considerado.
} 


\section{CONSIDERAÇÕES FINAIS}

O objetivo do presente artigo foi apresentar um balanço da terceira e última versão do Programa Nacional de Direitos Humanos, que completa 10 anos em dezembro de 2019, especialmente o Eixo II que aborda a temática dos Direitos Humanos e do Desenvolvimento. Tal reflexão se constitui numa tarefa necessária tendo em vista a constatação não apenas da falta de implementação de grande parte das propostas contidas no PNDH-3, mas também porque muitas ações e políticas tem se apresentado no sentido contrário ao que está estabelecido nesse Programa.

Além de descrever brevemente a trajetória do Programa Nacional de Direitos Humanos no Brasil, e reforçar a importância da Constituição Federal de 1988 no que se refere ao princípio da dignidade da pessoa humana, registramos algumas das resistências iniciais ao lançamento doPNDH-3, o que nos permitiu constatar que tais resistências não diminuíram nos anos que se seguiram. Ao contrário, constata-se hoje que os direitos humanos, inclusive, se tornassem o alvo preferencial de ataques por parte de setores do governo e de segmentos expressivos da sociedade brasileira.

Além das questões econômicas e da concepção de Estado, destacam-se ainda outros temas que estiveram presentes no PNDH-3 e que sofreram profundas alterações nos dez últimos anos, tais como a criminalização de movimentos sociais, o negacionismo climático, a priorização do agronegócio em detrimento da agroecologia, a legalização de um acentuado número de agrotóxicos, a violação dos direitos dos povos indígenas e quilombolas, as tentativas de desacreditar a pesquisa científica, a extinção de conselhos participativos e fiscalizadores de violações de direitos humanos, o cancelamento de editais voltados à produção audiovisual sobre minorias, a centralização de decisões e a falta de diálogo com as comunidades diretamente envolvidas, o enfraquecimento dos sindicatos, a diminuição e o desprestígio do serviço público, as mudanças nas concepções sobre trabalho escravo, entre outros.

A tentativa de enfatizar as mudanças econômicas e as concepções de Estado se justifica pela influência generalizada que incide em todas as diretrizes que compõem o EOII-DDH, o que, por mais que não nos ajude a compreender as implicações de modo pormenorizado, permite uma avaliação a respeito do que se tem feito - ou não - para atingir os objetivos constantes no PNDH-3.

Em síntese, o balanço aqui produzido revela um desalinhamento entre o que se pretendida sobre Desenvolvimento e Direitos Humanos no PNDH-3 e as decisões políticas, econômicas e sociais vislumbradas nos últimos 10 anos. Mesmo considerando que o Eixo II não tenha sofrido alterações quando do lançamento do PNDH-3, ao contrário do que ocorreu com outros eixos conforme demonstramos anteriormente, ocorre que suas propostas não foram contempladas, ou os caminhos adotados seguiram objetivos diametralmente opostos, sobretudo se considerarmos as decisões governamentais a partir de 2015, alheias ao combate às desigualdades e à participação da sociedade nas decisões sobre desenvolvimento.

Não bastasse esse "diagnóstico" que vai em direção contrária à proposta de desenvolvimento em sinergia com a valorização dos direitos humanos, nos parece que os últimos acontecimentos políticos transcendem o PNDH-3 e acaba por colapsar a própria Carta Magna. O olhar sobre os riscos que a democracia brasileira enfrenta já é objeto de preocupação e de análise de diversos autores, tais como Castells (2018) e Runciman (2019). Como efeito, desde a redemocratização do Brasil, a defesa a exaustão da democracia e dos direitos humanos, 
base de um autêntico Estado Democrático e Constitucional de Direito, nunca foi tão necessária.

\section{REFERÊNCIAS}

ADORNO, Sérgio. História e Desventura: o $3^{\circ}$. Programa Nacional de Direitos Humanos. Novos Estudos CEBRAP 86, março de 2010, p. 5-20.

ALMEIDA NETO, Antônio; SIQUEIRA, Lucila (orgs). Direitos Humanos e Cultura escolar. [digital]. São Paulo: Editora Alameda, 2017.

BOURDIEU, Pierre. Sobre o Estado: Cursos no Collége de France (1989-92). $1^{\text {a }}$ ed. São Paulo: Companhia das Letras, 2014.

BRASIL. Decreto $\mathbf{n}^{\circ}$ 7.037, de 21 de dezembro de 2009. Aprova o Programa Nacional de Direitos Humanos - PNDH-3 e dá outras providências. Brasília, 21 dez. 2009. Disponível em <www.gov.br>. Acesso em 25 out. 2019.

BRASIL. Decreto n 7.177, de 12 de maio de 2010. Altera o Anexo do Decreto no 7.037, de 21 de dezembro de 2009, que aprova o Programa Nacional de Direitos Humanos - PNDH-3. Brasília, 12 mai. 2010. Disponível em <www.gov.br>. Acesso em 25 out. 2019.

BRASIL. Emenda Constitucional n ${ }^{\circ}$ 95, de 15 de dezembro de 2016. Altera o Ato das Disposições Constitucionais Transitórias, para instituir o Novo Regime Fiscal, e dá outras providências. Brasília, 15 dez. 2016. Disponível em <www.gov.br>. Acesso, em 07 nov. 2019.

BRASIL. Lei $\mathbf{n}^{\mathbf{0}}$ 13.467, de 13 de julho de 2017. Altera a Consolidação das Leis do Trabalho (CLT) (...). Brasília, 13 jul. 2017. Disponível em <www.gov.br>. Acesso, em 07 nov. 2019.

CARVALHO, José Murilo. Cidadania no Brasil: o longo caminho. Rio de Janeiro: Civilização Brasileira, 2001.

CASARA, Rubens. Estado Pós-Democrático: neo-obscurantismo e gestão dos indesejáveis. Rio de Janeiro: Civilização Brasileira, 2018.

CASTELLS, Manuel. Ruptura: a crise da democracia liberal. Rio de Janeiro: Zahar, 2018.

COMPARATO, Fábio Konder. Afirmação histórica dos direitos humanos. São Paulo: Saraiva, 1999.

CONDSEF/FENADSEF. Em vídeo, Paulo Guedes promete vender todo o patrimônio público brasileiro. Confederação dos Trabalhadores no Serviço Público Federal, Seção Notícias, 20 mai. 2019. Disponível em <https://bit.ly/2JZoOG7>. Acesso em 07 nov. 2019.

CUNHA, Luiz A.Educação e religiões: a descolonização religiosa da escola pública. Belo Horizonte: Mazza Edições, 2013.

DIAS, Marina. 'Não se assustem se alguém pedir o AI-5', diz Guedes. Folha de São Paulo, Seção Mercado, 25 nov. 2019. Disponível em <https://bit.ly/36J5vKq>. Acesso em 10 dez. 2019.

DOWBOR, Ladislau. O fim da farsa: o fluxo financeiro integrado. In: SOUZA, Jessé; VALIM, Rafael. Resgatar o Brasil. São Paulo: Editora Contracorrente/Boitempo, 2018.

FERNANDES, Adriana et al. 'Se tem filiação partidária não é servidor, é militante; não vou dar esta-

bilidade', diz Guedes. Estadão, Seção Notícias, 05 nov. 2019. Disponível em $<$ https://bit.ly/2NplRAJ>. Acesso em 07 nov. 2019.

MARTÍNEZ-VARGAS, Ivan. Governo vai privatizar 17 estatais neste ano, diz Guedes. Folha de São Paulo, Seção Mercado, 20 ago. 2019. Disponível em <https://bit.ly/36JWjWC>. Acesso em: 07 nov. 2019.

MELLO, Marco Aurélio. 30 anos da Constituição Federal de 1988: uma história de sucesso.Discurso proferido em sessão solene no STF, em 04 de outubro de 2018, por ocasião do aniversário de 30 anos da Constituição Federal de 1988.

MENA, Fernanda. Economista de Bolsonaro, Paulo Guedes viveu mudança radical em Chicago. Folha de São Paulo, Seção Mercado, 09 out. 2018. Disponível em <https://bit.ly/2CluQgj>. 
Acesso em 07 nov. 2019.

PERTENCE, Sepúlveda (entrevista). Revista Carta Maior, 18/jan./2010.

PIKETTY, Thomas. E economia da desigualdade. $1^{\circ}$ ed. Rio de Janeiro: Intrínseca, 2015.

PILLA, Maria Cecilia Barreto Amorim; ROSSI, Amélia do Carmo Sampaio. Constituição de 1988: o avanço dos Direitos Humanos Fundamentais. Estudos Ibero-Americanos, Porto Alegre, v. 44, n. 2, p. 273-284, maio-ago. 2018.

ROSSI, Pedro; DWECK, Esther. O discurso econômico da austeridade e os interesses velados. In: GALLEGO, Esther S. (Org). O ódio como política: a reinvenção das direitas no Brasil. 1. ed. São Paulo: Boitempo, 2018.

RUNCIMAN, David. Como a democracia chega ao fim. São Paulo: Todavia, 2019.

SALOMÃO, Alexa. 'Dá para esperar 4 anos de um liberal-democrata após 30 de centro-esquerda?', diz Guedes. Folha de São Paulo, Seção Mercado, 03 nov. 2019. Disponível em $<$ https://bit.ly/2NLeliK>. Acesso em 07 nov. 2019.

SARLET, Ingo Wolfgang. Dignidade da Pessoa Humana e Direitos Fundamentais na Constituição Federal de 1988. 5. ed. Porto Alegre: Livraria do Advogado, 2007.

SEN, Amartya. Desenvolvimento como liberdade. São Paulo: Companhia das Letras, 2000.

SOUZA, Jessé. A elite do atraso: da escravidão à Lava Jato. Rio de Janeiro:Leya, 2017. 